\title{
Maternal glucocorticoid levels during incubation predict breeding success, but not reproductive investment, in a free-ranging bird
}

\author{
Devin Fischer ${ }^{1}$, Robby R. Marrotte ${ }^{1}$, Eunice H. Chin ${ }^{2, *}$, Smolly Coulson ${ }^{3}$ and Gary Burness ${ }^{3, \pm}$
}

\begin{abstract}
The hormone corticosterone (CORT) has been hypothesized to be linked with fitness, but the directionality of the relationship is unclear. The 'CORT-fitness hypothesis' proposes that high levels of CORT arise from challenging environmental conditions, resulting in lower reproductive success (a negative relationship). In contrast, the CORT-adaptation hypothesis suggests that, during energetically demanding periods, CORT will mediate physiological or behavioral changes that result in increased reproductive investment and success (a positive relationship). During two breeding seasons, we experimentally manipulated circulating CORT levels in female tree swallows (Tachycineta bicolor) prior to egg laying, and measured subsequent reproductive effort, breeding success, and maternal survival. When females were recaptured during egg incubation and again during the nestling stage, the CORT levels were similar among individuals in each treatment group, and maternal treatment had no effect on indices of fitness. By considering variation among females, we found support for the CORTadaptation hypothesis; there was a significant positive relationship between CORT levels during incubation and hatching and fledging success. During the nestling stage CORT levels were unrelated to any measure of investment or success. Within the environmental context of our study, relationships between maternal glucocorticoid levels and indices of fitness vary across reproductive stages.
\end{abstract}

KEY WORDS: Stressor, Corticosterone, Fitness, Avian, Tree swallow

\section{INTRODUCTION}

Within and among species individuals vary in the strategies used to maximize fitness, by adjusting the relative effort put into current versus future reproductive events (Williams, 2005; Hansen et al., 2016). There is ample evidence that increased energy expenditure and effort during one breeding bout results in decreased reproductive success, probability of re-nesting, or survival in subsequent bouts (Nager, 2006; Crossin et al., 2013; 2016; Harms et al., 2014; Bleu, Gamelon and Sæther, 2016; Henderson et al., 2017).

Glucocorticoids (GCs) have been hypothesized to be a mediator of the trade-off between current and future reproduction (Wingfield

${ }^{1}$ Environmental and Life Sciences Graduate Program, Trent University, Peterborough, Ontario, Canada K9L 0G2. ${ }^{2}$ Department of Biological Sciences, Simon Fraser University, Burnaby, British Columbia, Canada V5A 1S6. ${ }^{3}$ Department of Biology, Trent University, Peterborough, Ontario, Canada K9L 0G2.

*Present address: Biology Department, Capilano University, North Vancouver, British Columbia, Canada V7J 3H5

‡Author for correspondence (garyburness@trentu.ca)

(D) G.B., 0000-0002-1695-7179

This is an Open Access article distributed under the terms of the Creative Commons Attribution License (https://creativecommons.org/licenses/by/4.0), which permits unrestricted use, distribution and reproduction in any medium provided that the original work is properly attributed.

Received 27 June 2019; Accepted 21 January 2020 et al., 1998; Bleu, Gamelon and Sæther, 2016; Hansen et al., 2016). GCs are metabolic hormones that fluctuate daily with feeding and other activities, and under resting conditions regulate energy balance (Landys, Ramenofsky and Wingfield, 2006; Wilcoxen et al., 2011; Hau and Goymann, 2015). In response to an environmental stressor, GC levels increase rapidly, resulting in increased availability of metabolic substrates, and adjustment of behaviors toward immediate survival (Wingfield and Sapolsky, 2003; Romero, 2004) while inhibiting reproductive behavior and physiology (Sapolsky et al., 2000; Dantzer et al., 2014), i.e. the CORT-trade-off hypothesis (Patterson et al., 2014).

GCs are thought to play a role in translating environmental cues into adaptive physiological responses. In birds, the dominant GC is corticosterone (hereafter, CORT), and an elevation of baseline CORT levels may signal a poor quality environment or an individual in poor condition (Bonier et al., 2009b). Following this reasoning, Bonier et al. (2009a) formulated 'the CORT-fitness hypothesis', which predicts that individuals with higher circulating CORT levels would have lower fitness. In support of this, higher baseline CORT levels have been negatively associated with habitat quality, body condition, hatching success, and fledging success across various species, e.g. blue tits Cyanistes caeruleus (Henderson et al., 2017); tree swallows Tachycineta bicolor (Patterson et al., 2011); barn swallows Hirundo rustica (Saino et al., 2005); Adelie penguins Pygoscelis adeliae (Thierry et al., 2013).

In contrast, a positive relationship is predicted by 'the CORTadaptation hypothesis'. This hypothesis suggests that because CORT can mediate the mobilization of fuels, causing changes in behavior or physiology that can increase investment in reproduction, elevated CORT will lead to higher fitness during energetically demanding times (Wingfield and Sapolsky, 2003; Bonier et al., 2009a). Indeed, across a variety of species and life history strategies individuals with higher reproductive success have been reported to have higher CORT levels, e.g. eastern bluebirds Sialia sialis (Burtka et al., 2016); black-legged kittiwakes Rissa tridactyla (Chastel et al., 2005); petrels Macronectes spp. (Crossin et al., 2013); western bluebirds Sialia mexicana (Kleist et al., 2018); mourning doves Zenaida macroura (Miller et al., 2009).

In fact, there may exist no consistent relationship between CORT and fitness, due to a variety of factors masking directionality (Madliger and Love, 2016a). For example, a lack of relationship could be due to different functions of CORT; when resources are plentiful, elevated CORT could stimulate energy mobilization and parental provisioning; however, CORT could also be elevated in parents experiencing stressors (Vitousek et al., 2014). Even within a breeding season, different stages can have differing parental energetic requirements presumably requiring different levels of GC-mediated energy mobilization (Humphreys et al., 2006; Nager, 2006; Tulp et al., 2009; Sakaluk et al., 2018).

Most studies that have explored relations between CORT and fitness have been correlative. Although such studies are certainly 
informative (e.g. Bonier et al., 2009b), studies that manipulate CORT levels directly, and explore the resultant parental response are also needed. Using tree swallows as a model organism, we attempted to elevate maternal CORT experimentally prior to egg laying, and quantify subsequent variation in maternal reproductive investment and reproductive success over two breeding seasons. Females were captured shortly before egg laying and each received a silastic implant containing either CORT or left empty (Sham). An additional group of females we captured for the first time during early incubation but received no implant. Although we refer to these latter females as 'controls', we recognize they may represent a nonrandom sample and we interpret our results accordingly. We asked two primary questions: (1) how does maternal CORT influence reproductive investment and success? (2) Does the directionality of the relationship between maternal CORT and reproductive investment and success change between the incubation and nestling provisioning stages, given the increased energy expenditure and brood value during chick provisioning? If the CORT-fitness hypothesis were true, we expected to detect a negative relationship between maternal CORT and measures of reproductive investment and success. Conversely, if the CORTadaptation hypothesis were true, we expected to see a positive relationship between maternal CORT and reproductive investment and success.

\section{RESULTS}

\section{Morphology and hormonal measures of adult females}

We implanted 45 females with CORT-filled implants, and 44 with sham implants; an additional 23 females were captured for the first time during incubation and were allocated to the Control treatment (Table 1). There was no difference in pre-egg laying body mass between females allocated to the CORT and Sham groups (Table S1); females in the Control group were not captured prior to egg laying, so there was no pre-egg laying mass. Focusing on individuals that retained their implants, wing length and clutch initiation date did not differ significantly among treatments (Table S1). There was no significant difference between the Sham and CORT treatments in the percentage of females that retained their implants and subsequently laid eggs [Sham: 45\% (20 of 43), CORT: $31 \%$ (14 of 44$) ; \chi^{2}=0.865$, d.f. $=1, P=0.352$; Table 1 ; a single CORT and Sham female of unknown age were omitted from the analysis].

There was no significant difference by year in the number of implanted females that were recaptured during incubation $(\beta=0.800$, $\mathrm{SE}=0.509, \mathrm{z}=1.573, P=0.116, N_{2015}=34$ recaptured and 25 nonrecaptured, $N_{2016}=22$ recaptured and eight non-recaptured).

Table 1. Sample sizes of adult female tree swallows allocated to each maternal treatment group across 2 years

\begin{tabular}{|c|c|c|c|c|c|c|}
\hline & \multicolumn{2}{|c|}{ Sham } & \multicolumn{2}{|c|}{ CORT } & \multicolumn{2}{|c|}{ Control } \\
\hline & SY & ASY & SY & ASY & $\overline{S Y}$ & ASY \\
\hline Number of females implanted & 16 & 27 & 18 & 26 & - & - \\
\hline Number of females that laid & $3(9)$ & $17(24)$ & $5(6)$ & $9(18)$ & 11 & 10 \\
\hline $\begin{array}{l}\text { Number of females that } \\
\text { laid eggs that hatched }\end{array}$ & $2(7)$ & $16(23)$ & $4(5)$ & $9(16)$ & 8 & 10 \\
\hline
\end{tabular}

Sham: females had an empty silastic implant; CORT: females had a silastic implant filled with crystalline CORT; Control: females had no implant. Female age: SY (second-year); ASY (after second-year).

Bracketed values represent total number of individuals handled/implanted; non-bracketed values indicate sample sizes of birds with implants that were still present when the bird was recaptured during incubation.

Four females of unknown age are omitted from the table (1 CORT, 1 Sham, 2 Controls).
However, sham-implanted individuals were more likely to be recaptured than CORT-implanted $(\beta=1.115, \mathrm{SE}=0.468, \mathrm{z}=2.381$, $P=0.017, \mathrm{~N}_{\text {Sham }}=33$ recaptured and 11 non-recaptured, $N_{\text {CORT }}=23$ recaptured and 22 non-recaptured). Control birds were not included in the recaptured/not recaptured analysis because they were caught for the first time during incubation.

\section{Implants failed to raise long-term maternal CORT levels}

During incubation, females were recaptured on average 17.02 days $( \pm 0.63)$ after implantation (range 7 to 26 days). Contrary to expectations, when females were recaptured there was no difference in CORT levels among the three treatments (Table 2, Fig. 1A). Lay date (i.e. clutch initiation date) was also not a significant predictor of CORTinc (Table 2). However, older mothers (ASY, after second year) had higher CORTinc levels than second year (SY) mothers and levels differed between years (Table 2). During nestling provisioning, maternal baseline CORT (CORTnest) did not differ among treatments (Table 2, Fig. 1B), nor with any other fixed effects (Table 2).

\section{Maternal CORT levels did not predict reproductive investment}

Mean clutch size ( \pm s.e.) of females was 5.3 eggs \pm 0.1 (range $=3$ to 7 eggs per nest, $N=67$ nests). Reproductive investment during laying, measured as clutch mass, did not correlate with maternal CORT levels during incubation (CORTinc) nor with maternal treatment, although older birds had significantly heavier clutches (Table 3 ). Similarly, during the nestling stage, there was no relationship between either CORTnest or treatment on the number of female nest box visits (Table 3). Although maternal treatment did not influence nestling growth rate between days 3 and 7 , there was a marginally significant negative relationship between maternal CORTnest and nestling growth rate ( $P=0.092$, Table 3$)$. Maternal age influenced nestling growth rates, with nestlings from SY mothers having higher growth rates than nestlings from ASY mothers (Table 3).

\section{Maternal CORT levels during incubation predicted reproductive success}

As indices of reproductive success, we measured hatching success, nestling mass at day 14 post-hatch, and fledging success. Mothers with higher CORTinc had significantly higher hatching success (Table 4). Nestling mass at day 14 post-hatch was not predicted by either CORTnest or maternal treatment, although nestlings at the Nature Area site tended to be heavier (site: $P=0.064$; Table 4).

The probability of a nestling fledging significantly increased with maternal CORT levels measured during incubation (fledging success A, Table 4). There was a marginally significant negative relationship during the nestling phase (fledging success $B$, $P=0.060$ ), but this was driven, at least in part, by a control female with the lowest hormone levels $(2.34 \mathrm{ng} / \mathrm{ml})$ yet $100 \%$ fledging success. Maternal treatment had no effect on fledging success (fledging success A or B, Table 4). Fledging success tended to be higher at the Sewage Lagoon site (fledging success A, site: $P=0.062$; Table 4)

\section{Maternal return rate was not significantly predicted by maternal CORT levels}

Twenty-nine of 67 (43\%) females (Sham, CORT or Control) returned in the year after they were initially caught, and all returning females returned to the same breeding site where initially caught. The number of females included in the analysis differs from totals in Table 1, because only females with CORT measurements were included. The probability that a female returned tended to increase 
Table 2. Factors contributing to variation in CORT levels in female tree swallows during incubation (CORTinc) and the nestling stage (CORTnest)

\begin{tabular}{|c|c|c|c|c|c|c|c|}
\hline Response variable & Fixed effects & $\beta$ & s.e. & d.f. & $\mathrm{t}$ & $P$ & $\mathrm{R}^{2}$ \\
\hline \multirow[t]{8}{*}{ CORTinc (ng/ml) } & Intercept & 2.753 & 3.578 & 1,38 & 0.769 & 0.447 & 0.227 \\
\hline & Treatment (CORT) & -0.611 & 0.315 & 1,38 & -1.943 & 0.060 & \\
\hline & Treatment (Sham) & -0.366 & 0.276 & 1,38 & -1.325 & 0.193 & \\
\hline & Age (ASY) & 0.770 & 0.327 & 1,38 & 2.358 & 0.024 & \\
\hline & Lay date & 0.000 & 0.025 & 1,38 & 0.008 & 0.993 & \\
\hline & Site (Nature Area) & -0.459 & 0.255 & 1,38 & -1.800 & 0.080 & \\
\hline & Sample time & -0.005 & 0.004 & 1,38 & -1.233 & 0.225 & \\
\hline & Year & -0.755 & 0.291 & 1,38 & -2.591 & 0.014 & \\
\hline \multirow[t]{7}{*}{ CORTnest (ng/ml) } & Intercept & 2.834 & 4.272 & 1,17 & 0.664 & 0.516 & 0.071 \\
\hline & Treatment (CORT) & 0.593 & 0.369 & 1,17 & 1.610 & 0.126 & \\
\hline & Treatment (Sham) & 0.218 & 0.292 & 1,17 & 0.748 & 0.465 & \\
\hline & Age (ASY) & 0.086 & 0.489 & 1,17 & 0.176 & 0.862 & \\
\hline & Lay date & -0.005 & 0.028 & 1,17 & -0.163 & 0.872 & \\
\hline & Site (Nature Area) & 0.336 & 0.362 & 1,17 & 0.926 & 0.367 & \\
\hline & Sample time & 0.002 & 0.004 & 1,17 & 0.638 & 0.532 & \\
\hline
\end{tabular}

Year was not included for CORTnest, because data were collected in a single year.

Statistically significant main effects are in bold.

with her CORTinc levels $(P=0.054)$ and number of fledglings in the previous year (return rate A: $P=0.056$, Table 5). There was no significant effect of CORTnest or maternal treatment on the likelihood of a female returning to the nest sites the following year (Table 5).

\section{DISCUSSION}

Our data support the CORT-adaptation hypothesis. During egg incubation, CORT levels of female tree swallows were positively related to two measures of reproductive success (hatching and fledging success) and positively (albeit non-significantly) with female return rates. During the nestling stage, there was no relationship between CORT and indices of either reproductive investment or reproductive success. During neither period did we detect a significant negative relationship between CORT and fitness, as predicted by the CORT-fitness hypothesis.

\section{Maternal CORT levels during incubation}

We tested for a relationship between maternal CORTinc and clutch mass (as a single measure of reproductive investment), and hatching success and survival to fledging as measures or reproductive success (Bonier et al., 2009b; Schoenle et al., 2017). We found no relation between CORTinc and clutch mass; however, female tree swallows with higher CORTinc levels had greater hatching success and higher fledging success. The positive relationship we detected with hatching success may be due to CORT mobilizing energy stores, and thus allowing for increased reproductive effort (Riechert et al., 2014). However, positive (common terns Sterna hirundo) (Riechert et al., 2014), negative (zebra finches) (Khan et al., 2016), and null relationships (red-winged blackbirds) (Schoenle et al., 2017) have all been reported between maternal CORT and hatching success. Differences in the directionality of the relationships are presumably due to various environmental factors, including weather conditions (Schoenle et al., 2017), food (Riechert et al., 2014), and/ or resource availability (Breuner and Burk, 2019).

A positive relationship between CORTinc and fledging success is consistent with relationships reported in eastern bluebirds (Burtka et al., 2016) and blue tits (Henderson et al., 2017). However in tree swallows, both negative (Bonier et al., 2009b) and statistically nonsignificant (Madliger and Love, 2016a) relationships between CORTinc and number of fledglings have been reported. A positive relationship, such as we detected, between maternal CORT during incubation and fledging success might be expected if the relationship were mediated through maternal transfer of CORT into the egg, leading to higher begging rates and body size in nestlings of mothers with higher CORT (Bowers et al., 2016). However, this would be a plausible mechanism only if CORT levels during incubation correlated with levels pre-laying, as has been found in other tree swallow populations (Ouyang et al., 2011a,b); something we did not evaluate in our study.

A positive relationship between maternal CORT and fitness (CORT-adaptation hypothesis) should emerge when CORT levels are increased to meet higher energetic demands associated with reproduction (Bonier et al., 2009a; Crossin et al., 2013; Rivers et al., 2017). During incubation, individuals may experience more unpredictable stressors than during the nestling stage (Romero, 2002). For example, challenging environmental conditions such as lower temperatures and scarcer food resources in early spring can cause a negative relationship between both temperature and foraging success and baseline CORT levels, depending on the fitness and environmental measure used (Angelier et al., 2007; Wingfield et al., 2010; Ouyang et al., 2015). Because higher baseline levels may prime the body to perform better under stress, females with higher baseline CORT during incubation in our study may have been better able to meet these challenges (Romero, 2002).

\section{Maternal CORT levels during chick rearing}

We predicted that if there were a relationship between CORT and reproductive investment and success, it would most likely emerge post-hatch, given the higher maternal energy expenditure required during chick rearing than during incubation (Nilsson and Råberg, 2001; Humphreys et al., 2006; Sakaluk et al., 2018; but see Williams, 2018). However, female CORT levels during chick rearing were unrelated to any measure of reproductive investment (nest box visits and nestling growth rate) nor any measure of reproductive success (nestling mass at day 14 and fledging success). Despite our inability to detect relationships, others have reported that individuals with higher baseline CORT levels during chick rearing had higher parental foraging effort, provisioning rates, and energy transfer to the nestlings, e.g. macaroni penguins Eudyptes chrysolophus (Crossin et al., 2012); tree swallows (Bonier et al., 2011); mourning doves (Miller et al., 2009). Across studies, differences in the relationship between CORT and reproductive success may be due to various fitness measures used, the relative importance of paternal investment, or environmental variation. 

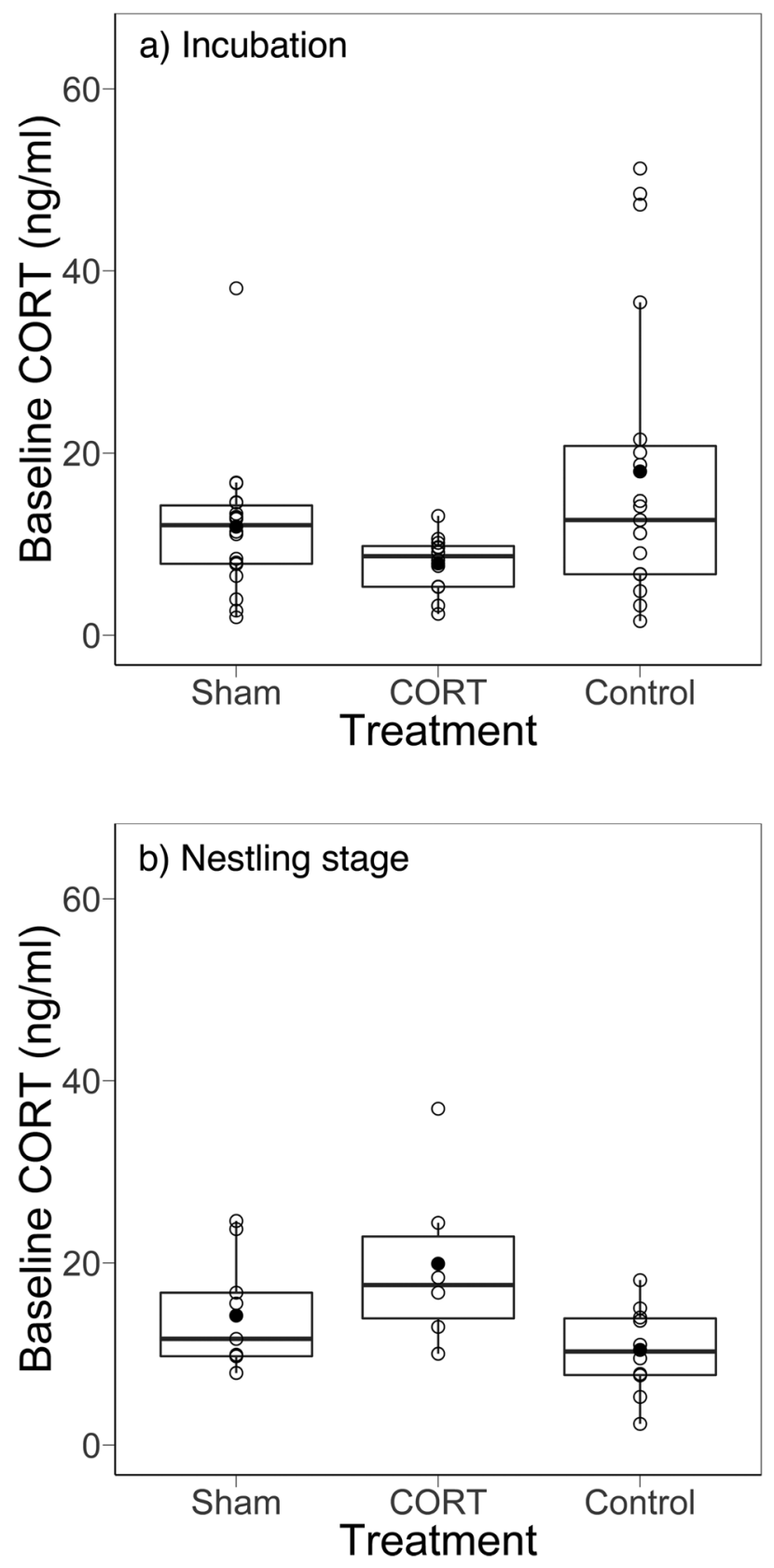

Fig. 1. There was no significant difference among treatments in plasma corticosterone levels of female tree swallows when measured during (A) incubation and (B) nestling stage. Individuals in the CORT treatment had a single silastic implant containing crystalline CORT, those in the Sham treatment had an empty implant, while Control birds had no implant. The black circle indicates the mean; the thick horizontal line is the median. Individual data points are shown.

While female tree swallows are solely responsible for egg incubation, nestling provisioning is shared with the male (Winkler et al., 2020). As a result, variation in paternal quality may obscure relationships between maternal CORT and investment during the nestling stage. A lack of relationship between CORTnest and female nest box visits has been found in bluebirds (Davis and Guinan, 2014) and other populations of tree swallows (Patterson et al., 2011), suggesting variation among females in their glucocorticoid levels may not directly reflect maternal behavior. In contrast, Madliger and Love (2016b) found that higher baseline CORTnest in female tree swallows correlated with lower rates of maternal provisioning; however, males compensated for the females' low rates by increasing their own provisioning rates such that nestlings were not affected. Similarly, Patterson et al. (2011) suggested male tree swallows could compensate for decreased provisioning of their mates, although no male compensation for reduced maternal performance has also been found (Hogle and Burness, 2014). Given the importance of male provisioning to nestling mass gain (Lendvai and Chastel, 2010; Madliger and Love, 2016b; Nomi, 2018), male nest box visits and paternal quality need to be considered when predicting a pairs' reproductive investment in a nest. Future studies should include male CORT levels, and their relationship with male feeding rates and reproductive success, as in Ouyang et al. (2011a,b).

The directionality of the relationship between maternal CORT and fitness varies among life stages, populations and species (e.g. Bonier et al., 2009a). Some of this variation is presumably due to the context-dependency of the CORT-fitness relationship and variation in environmental conditions (Burtka et al., 2016; Madliger and Love, 2016b). For example, experimental elevation of maternal CORT levels increased brood mortality in tree swallows, but only when weather conditions were benign (Ouyang et al., 2015). Our inability to detect relationships between maternal hormone levels during chick rearing and reproductive success could be due to the influence of such factors as food availability or weather, both of which could affect body condition and reproductive success of the mother (Schoech et al., 2007; Madliger and Love, 2016a). Maternal baseline CORT may also depend on the habitat type in which female tree swallows were breeding (Madliger and Love, 2016b). While we found no significant difference in reproductive investment between the two study sites, we did find that CORTinc and fledging success tended to be higher at one of our sites (Sewage Lagoon). Reproductive success may perhaps be mediated by a relationship between CORT and foraging conditions (Henderson et al., 2017), which could change from incubation to the nestling stage.

\section{No relationship between CORT and return rates}

We found a borderline $(P=0.054)$ positive relationship between CORTinc and the probability of whether a female returned to the breeding sites the following year. One explanation for the lack of significance is that the relationship between CORT levels and return rates may be non-linear. For example, in cliff swallows (Petrochelidon pyrrhonota), highest return rates were seen in individuals with intermediate baseline CORT levels, which could be due to stabilizing selection on CORT levels acting against the detrimental effects of very high or low CORT (Brown et al., 2005; Bonier et al., 2009a). Additionally, environmental variables (Clark et al., 2018) or an individual's reproductive success may better predict return rates than baseline CORT: the positive (albeit non-significant) effect of fledgling number on maternal return rates that we detected suggests that females with higher reproductive success are more likely to return to a certain area to breed (Bonier et al., 2009b). Thus, CORT may affect return rates and survival indirectly, by affecting fledging success (Shitikov et al., 2017; Weegman et al., 2017).

\section{Efficacy of silastic implants to raise plasma glucocorticoids}

We implanted pre-egg laying females with CORT-filled silastic implants, but when females were recaptured during early-to midincubation (mean \pm s.e.: 17.0 days \pm 0.6 after implantation), the baseline CORT levels of implanted birds did not differ from unmanipulated birds. However, CORT-implanted individuals had a lower probability of recapture during incubation, consistent with a negative relationship between experimental CORT elevation and 
Table 3. Factors contributing to variation in reproductive investment in female tree swallows

\begin{tabular}{|c|c|c|c|c|c|c|c|}
\hline Measures of maternal investment & Fixed effects & $\beta$ & s.e. & d.f. & $\mathrm{t}$ & $P$ & $\mathrm{R}^{2}$ \\
\hline \multirow[t]{7}{*}{ Clutch mass $(\mathrm{g})$} & Intercept & 7.712 & 1.295 & 1,35 & 5.954 & $<0.001$ & 0.127 \\
\hline & CORTinc & 0.139 & 0.457 & 1,35 & 0.305 & 0.762 & \\
\hline & Treatment (CORT) & 0.368 & 0.848 & 1,35 & 0.434 & 0.667 & \\
\hline & Treatment (Sham) & 0.540 & 0.761 & 1,35 & 0.709 & 0.483 & \\
\hline & Maternal age (ASY) & 1.514 & 0.733 & 1,35 & 2.064 & 0.047 & \\
\hline & Site (Nature Area) & -0.936 & 0.656 & 1,35 & -1.427 & 0.162 & \\
\hline & Year & -0.407 & 0.635 & 1,35 & -0.640 & 0.526 & \\
\hline \multirow[t]{7}{*}{ Nest box visits (per chick per hour) } & Intercept & 2.697 & 1.451 & 1,16 & 1.858 & 0.082 & 0.101 \\
\hline & CORTnest & -0.382 & 0.476 & 1,16 & -0.802 & 0.434 & \\
\hline & Treatment (CORT) & 0.295 & 0.759 & 1,16 & 0.388 & 0.703 & \\
\hline & Treatment (Sham) & -0.292 & 0.637 & 1,16 & -0.459 & 0.653 & \\
\hline & Site (Nature Area) & 0.696 & 0.640 & 1,16 & 1.087 & 0.293 & \\
\hline & Male visits per chick per hour & 0.569 & 0.293 & 1,16 & 1.938 & 0.070 & \\
\hline & Maternal age (ASY) & 0.131 & 0.662 & 1,16 & 0.198 & 0.846 & \\
\hline \multirow{8}{*}{$\begin{array}{l}\text { Growth rate (mass gain per chick per day } \\
\text { from day } 3 \text { to day } 7 \text { post-hatch) }\end{array}$} & Intercept & 3.619 & 0.390 & $1,43.662$ & 9.279 & $<0.001$ & (M) 0.271 \\
\hline & CORTnest & -0.250 & 0.145 & $1,42.800$ & -1.722 & 0.092 & (C) 0.579 \\
\hline & Treatment (CORT) & 0.104 & 0.202 & $1,21.465$ & 0.516 & 0.611 & \\
\hline & Treatment (Sham) & 0.135 & 0.193 & $1,22.072$ & 0.698 & 0.492 & \\
\hline & Site (Nature Area) & 0.226 & 0.177 & $1,25.404$ & 1.279 & 0.212 & \\
\hline & Maternal age (ASY) & -0.859 & 0.217 & 1, 23.692 & -3.957 & $<0.001$ & \\
\hline & Nestling sex (male) & -0.149 & 0.347 & $1,110.4111$ & -0.430 & 0.668 & \\
\hline & CORTnest $x$ nestling sex & 0.102 & 0.138 & $1,110.421$ & 0.739 & 0.461 & \\
\hline
\end{tabular}

CORTinc and CORTnest refer to maternal CORT levels during incubation and the nestling stage, respectively.

Year was not included in analyses of nest box visits or growth rate, because CORTnest was measured in a single year only.

Adjusted $\mathrm{R}^{2}$ values are provided for models without random effects; marginal $(\mathrm{M})$ and conditional $(\mathrm{C}) \mathrm{R}^{2}$ values are provided for models with random effects. Statistically significant main effects are in bold.

survival (Schoenle et al., 2021). Across species, silastic implants have been successfully used to raise CORT levels for anywhere from a few days (Astheimer et al., 2000; Hayward and Wingfield, 2004; Criscuolo et al., 2005; Martin et al., 2005; Angelier et al.,
2007 ) to 3 weeks post-implantation in vivo (Ouyang et al., 2013) and in vitro (Newman et al., 2010). However, the use of implants to raise CORT levels has not been consistently successful (Crossin et al., 2012; Ouyang et al., 2013; Hau and Goymann, 2015; Lattin

Table 4. Factors contributing to variation in reproductive success in female tree swallows

\begin{tabular}{|c|c|c|c|c|c|c|c|}
\hline Measures of maternal reproductive success & Fixed effects & $\beta$ & s.e. & d.f. & $z$ or t & $P$ & $\mathrm{R}^{2}$ \\
\hline \multirow[t]{7}{*}{ Hatching success } & Intercept & -0.831 & 1.046 & 1,263 & -0.795 & 0.427 & (M) 0.220 \\
\hline & CORTinc & 0.969 & 0.378 & 1,263 & 2.563 & 0.010 & (C) 0.461 \\
\hline & Treatment (CORT) & 1.260 & 0.744 & 1,263 & 1.694 & 0.090 & \\
\hline & Treatment (Sham) & 0.418 & 0.688 & 1,263 & 0.609 & 0.543 & \\
\hline & Site (Nature Area) & -0.818 & 0.572 & 1,263 & -1.430 & 0.153 & \\
\hline & Year & -0.285 & 0.530 & 1,263 & -0.538 & 0.591 & \\
\hline & Age (ASY) & 0.599 & 0.598 & 1,263 & 1.002 & 0.316 & \\
\hline \multirow[t]{6}{*}{ Nestling mass at day 14 post-hatch } & Intercept & 22.219 & 0.963 & $1,29.767$ & 23.082 & $<0.001$ & (M) 0.086 \\
\hline & CORTnest & -0.587 & 0.363 & $1,26.735$ & -1.618 & 0.117 & (C) 0.239 \\
\hline & Treatment (CORT) & 0.291 & 0.592 & $1,22.059$ & 0.492 & 0.628 & \\
\hline & Treatment (Sham) & -0.356 & 0.575 & $1,21.742$ & -0.619 & 0.543 & \\
\hline & Site (Nature Area) & 0.972 & 0.503 & $1,27.232$ & 1.934 & 0.064 & \\
\hline & Age (ASY) & 0.226 & 0.600 & $1,27.066$ & 0.376 & 0.710 & \\
\hline \multirow[t]{7}{*}{ Fledging success $A$} & Intercept & -2.437 & 1.450 & 1,228 & -1.681 & 0.093 & (M) 0.333 \\
\hline & CORTinc & 1.448 & 0.551 & 1,228 & 2.627 & 0.009 & (C) 0.670 \\
\hline & Treatment (CORT) & 0.916 & 0.998 & 1,228 & 0.918 & 0.359 & \\
\hline & Treatment (Sham) & 0.538 & 0.927 & 1,228 & 0.580 & 0.562 & \\
\hline & Site (Nature Area) & -1.542 & 0.826 & 1,228 & -1.868 & 0.062 & \\
\hline & Age (ASY) & 1.029 & 0.849 & 1,228 & 1.212 & 0.225 & \\
\hline & Year & -0.491 & 0.684 & 1,228 & -0.718 & 0.473 & \\
\hline \multirow[t]{6}{*}{ Fledging success B } & Intercept & 6.423 & 2.922 & 1,144 & 2.198 & 0.028 & (M) 0.186 \\
\hline & CORTnest & -2.029 & 1.078 & 1,144 & -1.883 & 0.060 & (C) 0.591 \\
\hline & Treatment (CORT) & 0.207 & 1.295 & 1,144 & 0.160 & 0.873 & \\
\hline & Treatment (Sham) & -0.653 & 1.190 & 1,144 & -0.549 & 0.583 & \\
\hline & Site (Nature Area) & -0.325 & 1.202 & 1,144 & -0.270 & 0.787 & \\
\hline & Age (ASY) & 0.819 & 1.461 & 1,144 & 0.561 & 0.576 & \\
\hline
\end{tabular}

Each model includes maternal ID as a random effect; marginal (M) and conditional $(C) \mathrm{R}^{2}$ values are provided.

There were two analyses of fledging success (A and B), with predictors including either CORTinc or CORTnest, respectively.

Year was not included in analyses of nestling mass at day 14 or fledging success B, because CORTnest was measured in a single year only.

Statistically significant main effects are in bold. 
Table 5. Factors predicting the return rate in female tree swallows in the following year

\begin{tabular}{|c|c|c|c|c|c|c|}
\hline Response variable & Fixed effects & $\beta$ & s.e. & d.f. & $z$ & $P$ \\
\hline \multirow[t]{8}{*}{ Return rate $A$} & Intercept & -3.738 & 1.686 & 1,34 & -2.217 & 0.027 \\
\hline & CORTinc & 1.177 & 0.612 & 1,34 & 1.925 & 0.054 \\
\hline & Treatment (CORT) & 1.104 & 1.063 & 1,34 & 1.038 & 0.299 \\
\hline & Treatment (Sham) & 1.049 & 0.962 & 1,34 & 1.091 & 0.275 \\
\hline & Number of fledglings & 0.538 & 0.281 & 1,34 & 1.913 & 0.056 \\
\hline & Year & 0.240 & 0.820 & 1,34 & 0.293 & 0.769 \\
\hline & Age (ASY) & -2.077 & 1.069 & 1,34 & -1.943 & 0.052 \\
\hline & Site (Nature Area) & 0.758 & 0.939 & 1,34 & 0.808 & 0.419 \\
\hline \multirow[t]{7}{*}{ Return rate B } & Intercept & -2.562 & 3.211 & 1,15 & -0.798 & 0.425 \\
\hline & CORTnest & 0.337 & 1.066 & 1,15 & 0.317 & 0.752 \\
\hline & Treatment (CORT) & 0.579 & 1.678 & 1,15 & 0.345 & 0.730 \\
\hline & Treatment (Sham) & 0.570 & 1.262 & 1,15 & 0.452 & 0.651 \\
\hline & Number of fledglings & 0.636 & 0.409 & 1,15 & 1.557 & 0.119 \\
\hline & Age (ASY) & -0.730 & 1.545 & 1,15 & -0.472 & 0.637 \\
\hline & Site (Nature Area) & 1.073 & 1.542 & 1,15 & 0.696 & 0.487 \\
\hline
\end{tabular}

There were two analyses of return rate (A and B), with predictors including either CORTinc or CORTnest, respectively.

Year was not included in analyses of return rate B, because CORTnest was measure in 1 year only.

Statistically significant main effects are in bold.

et al., 2016; Torres-Medina et al., 2018). Although the implants used in our study may have failed to release CORT, this seems unlikely given that in vitro studies have shown that CORT continues to be released across the membrane over 4 weeks (Newman et al., 2010). More likely, the implants resulted in decreased secretion of endogenous CORT via negative feedback, or increased clearance of CORT from the blood via increased excretory activity (Newman et al., 2010; Henriksen et al., 2011; Robertson et al., 2015).

Rather than experimentally manipulate CORT levels via implants, an alternative approach may be to manipulate maternal condition, such as with feather clipping (Rivers et al., 2017), predator experiments (Clinchy et al., 2011; Pitk et al., 2012), or density manipulations (Bentz et al., 2013). Such an approach would encompass how maternal CORT levels change based on how each female perceives her condition/environment, how that is reflected in blood CORT levels, and how those levels might influence the next generation (Madliger and Love, 2016a; Rivers et al., 2017).

\section{Conclusions}

The differing directionality of relationship between CORT and fitness among studies and species raises the simple question: is there is a consistent relationship to be found among individuals within a population? Many factors can affect both CORT and fitness, including condition (Love et al., 2005), life-history stage (Romero, 2002), weather (Pakkala et al., 2016), habitat variability (Madliger and Love, 2016b), and resource availability (Breuner and Burk, 2019). If it can be reasonably assumed that these will always differ among individuals, then perhaps there is no consistent relationship, and any that may be detected will always be context-dependent (Madliger and Love, 2016a). Recent meta-analyses that seek to understand relationships between CORT and fitness across taxa, and studies that identify factors that contribute to context-dependence, are particularly valuable (Sorenson et al., 2017; Breuner and Burk, 2019; Schoenle et al., 2021; Bonier and Cox, 2020).

The use of integrative measures of CORT may be an alternative way to improve our understanding of the relationship between CORT and fitness. By measuring CORT deposited in feathers during growth, or metabolites excreted in feces, it may be possible to infer CORT levels over multiple days of the incubation or nestling stage (Lucas et al., 2006; Bortolotti et al., 2008; Romero and Fairhurst, 2016). For example, giant petrels that successfully bred had higher feather CORT levels than failed breeders, but were less likely to breed the following year, a pattern that was not observed using plasma CORT from these same individuals (Crossin et al., 2013). Ideally, studies could be extended over the winter, as has been done recently in adult tree swallows (Vitousek et al., 2018). This would help elucidate the longer-term effects of maternal CORT on offspring and maternal and fitness.

\section{MATERIALS AND METHODS \\ Study location and species}

All protocols were approved by Trent University Animal Care Committee, with a handling, banding and collection permit provided by Canadian Wildlife Service, Environment Canada. Our study took place during spring and summer 2015 and 2016, using tree swallows, a small, migratory, aerial insectivore, which breeds across central and northern North America (Winkler et al., 2020). They are cavity nesters that readily occupy artificial nest boxes, and both sexes begin nest building in late April to early May, with laying occurring through May and June. Most populations lay only one clutch of five or six eggs per season; the female then incubates the eggs for about 14 days. Chicks are fed by both parents and fledge at approximately 21 days post-hatch.

We had two field sites near Peterborough Ontario, Canada (University Nature Area: $44^{\circ} 21^{\prime} \mathrm{N}, 78^{\circ} 17^{\prime} \mathrm{W}$; and Lakefield Township Sewage

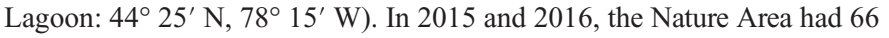
and 70 boxes, respectively; Sewage Lagoon had 50 and 52 nest boxes. The Nature Area consisted of open woodland with long grasses, shrubs and scattered apple (Malus pumila), buckthorn (Rhamnus cathartica), red cedar (Juniperus virginiana), white cedar (Thuja occidentalis), and dogwood (Cornus florida). The immediate landscape around boxes at the Sewage Lagoon was exposed soil and grasses; the greater surrounding area was farmland consisting of both crop and pasture land. Nest boxes at the Sewage Lagoon were 5-10 $\mathrm{m}$ from the water.

\section{Experimental manipulation of maternal CORT levels}

Nest boxes were monitored daily beginning 6 May in both years. When nests were about $75 \%$ formed (when cup-shaped or when feathers were present), we captured females using cardboard trapdoors over the nest box opening, or by surprising birds sitting in nest boxes. In 2015, seven females were caught at night (between 2200 and 2400 h) by surprising birds sitting in nest boxes (no females were found in nest boxes at night in 2016). Upon capture, females were randomly assigned to CORT or Sham treatment groups (Table 1). We sterilized the skin of the right flank with $70 \%$ ethanol, made a $4 \mathrm{~mm}$ subcutaneous incision, and inserted a sterilized $10 \mathrm{~mm}$ silastic tube (ID $1.47 \mathrm{~mm}$ and OD $1.96 \mathrm{~mm}$, Dow Corning 508-006) filled with crystalline CORT (Sigma-Aldrich, C2505) that was sealed with silicone sealant (732 Dow Corning) at both ends (CORT treatment). To each 
implant, we added a single hole using a $30 \mathrm{G}$ needle (Ouyang et al., 2013). The design of our implants followed that of Ouyang et al. (2013), who used a $7 \mathrm{~mm}$ long implant (ID $1.5 \mathrm{~mm}$ ), sealed at both ends, and punctured with a single $0.3 \mathrm{~mm}$ hole. In great tits (Parus major) this design increased CORT levels by $\sim$ twofold above baseline for approximately 30 days postimplantation (Table 1 in Ouyang et al., 2013). Sham treatment tree swallows received sterilized empty implants. Empty implants weighed approximately $0.02 \mathrm{~g}$ and held an average of $0.007 \mathrm{~g} \pm 0.0007 \mathrm{~g}$ of CORT. Once the implant was inserted, the incision in the skin was sealed with a drop of $3 \mathrm{M}$ Vetbond (no. 1469SB). Each female was then aged as SY, or ASY (Pyle et al., 1987). Flattened wing length was measured with a standard ruler with a wing stop $( \pm 1 \mathrm{~mm})$, mass was measured with a Pesola spring scale $( \pm 0.25 \mathrm{~g})$. All birds (including any males caught inadvertently) were banded with a federal aluminum numbered leg band (Canadian Wildlife Service) and released. Birds were held for no more than $10 \mathrm{~min}$ before release. In 2016 and 2017, any previously banded female from 2015 or 2016 was counted as a returned bird in the return rate analysis regardless of whether they hatched a clutch that year.

We allocated females to the Control group if they were not caught prior to laying, either because they did not enter the nest box while it had a trap, or because they began laying earlier than we expected. Although these females did not receive an implant before egg laying, they were handled and measured beginning during incubation (sample sizes in Table 1).

\section{Nest and egg monitoring}

Nest boxes were monitored daily throughout the nest-building and laying period, and when eggs were discovered, eggs were numbered with a black marker and weighed $( \pm 0.01 \mathrm{~g})$ using a digital balance. One female had a lay date of 15 June, which was greater than three standard deviations from the population mean (21 May). We did not consider this female further because we suspected it was re-nesting after a failed first attempt. All other nests were included in statistical analyses.

\section{Nestling measurements}

Beginning on day 12 of incubation (incubation day $0=$ first day no new eggs were laid, and eggs were warm to the touch), nest boxes were checked twice daily. The hatch day of the first nestling was defined as day 0 for that nest. It was not possible to match nestlings to egg identity. We marked the talons of nestlings with colored nail polish to distinguish individuals, until we banded them on day 10 post-hatch with aluminum numbered leg bands (Canadian Wildlife Service). Nestlings were weighed at hatch with an egg scale $( \pm 0.01 \mathrm{~g})$, and on days $3,7,10,13$, and 14 post-hatch with a Pesola spring scale $( \pm 0.25 \mathrm{~g})$. Beginning on day 18 post-hatch, we checked nest boxes daily by partially opening the door to determine fledging success. To guard against pre-mature fledging, the nest box opening was blocked for 1 min after checking, and when the blocking was removed the box was observed for $5 \mathrm{~min}$ from a distance of a few meters; no instances of premature fledging were observed.

\section{Blood sampling procedure}

We recaptured adult females in nest boxes between day 2 and 5 of incubation (both years) and between day 3 and 6 post-hatch during chick rearing (in 2016 only) between 0600 and $1200 \mathrm{~h}$. Upon capture, we collected a $100 \mu \mathrm{l}$ blood sample from the brachial vein using a micro-capillary tube within $3 \mathrm{~min}$ of the female entering the nest box. The mean time taken to draw blood ( \pm s.e.) was $125 \pm 5 \mathrm{~s}(N=61)$ during incubation, and $115 \pm 6 \mathrm{~s}(N=26)$ during the nestling stage. Blood samples were kept on ice for up to $8 \mathrm{~h}$. Samples were then centrifuged for 4 min at $19,200 \times \boldsymbol{g}$ (Thermo IEC Micro-MB) before plasma and red blood cells were frozen separately at $-80^{\circ} \mathrm{C}$. Prior to release, we recorded female body mass and marked the tail feathers and right primaries with a spot of white acrylic paint to distinguish females from males during subsequent behavioral observations (Whittingham et al., 2003; Bonier et al., 2011). If the female had not been captured previously (i.e. she was to become a Control female), upon first capture during incubation we recorded her headbill length and wing length, and banded her.

We collected nestling blood samples $(50 \mu 1)$ from the brachial vein on days 7 or 8 , and 13 post-hatch. Samples taken on day 7 or 8 post-hatch were for molecular sexing and were added to $1 \mathrm{ml}$ of lysis buffer in the field and subsequently stored at $-20^{\circ} \mathrm{C}$. Samples collected on day 13 were centrifuged and plasma was stored at $-80^{\circ} \mathrm{C}$ (as part of a separate study).

\section{Adult behavioral observation}

On day 7 or 8 post-hatch between 0830 and $1400 \mathrm{~h}$, nest boxes were observed from a distance of $10 \mathrm{~m}$ for $1 \mathrm{~h}$ (Lendvai et al., 2015), during which we counted the number of visits made by males and females to the nest box. This was the maximum distance at which it was still possible to distinguish the sex of the adult entering the box through binoculars. Observations made mid-day have been shown to provide the best estimates of feeding rate, although 1-h observations periods done at any time of day predict total daily feeding rates (Lendvai et al., 2015).

\section{Lab procedures}

\section{CORT radioimmunoassay}

Plasma samples were analyzed for total CORT in duplicate using a ${ }^{1251}$ radioimmunoassay (MP Biomedicals \#07120103) following the manufacturer's instructions (Washburn et al., 2002). This assay has low cross-reactivity with deoxycorticosterone $(0.34 \%)$, testosterone $(0.10 \%)$, cortisol $(0.05 \%)$, aldosterone $(0.03 \%)$, and progesterone $(0.02 \%)$. Plasma was diluted 1:25 (10 $\mu \mathrm{l}$ of plasma plus $240 \mu \mathrm{l}$ of assay buffer). Samples that were not detectable were set to the lowest point on the standard curve (3.125 ng/ml), following Hogle and Burness (2014). We did not extract plasma because a serial dilution of non-extracted plasma pooled from five individuals was parallel to the standard curve. A total of 23 individual assays was performed. To calculate the inter-assay coefficient of variation $(\mathrm{CV})$ we ran duplicates of the kit 'low' and 'high' controls in each assay. The interassay $\mathrm{CV}$ was $8.6 \%$ and $7.4 \%$ for the low and high controls, respectively. To calculate the intra-assay $\mathrm{CV}$, in a single assay we included four replicates of the low and high controls. The intra-assay CVs were $13.4 \%$ and $7.9 \%$, respectively.

\section{Molecular sexing protocol}

Maternal CORT may facilitate sex-biased investment in nestlings (Love et al., 2005; Love and Williams, 2008). To evaluate this possibility, nestling blood samples taken on day 7 or 8 post-hatch were used for genetic sexing using the CHD1W and CHD1Z genes (Fridolfsson and Ellegren, 1999; Hogle and Burness, 2014). DNA extraction was done using DNEasy blood and tissue kits (Qiagen 69506). A touchdown PCR procedure was used with $10 \mathrm{ul}$ volumes consisting of $1.2 \mu \mathrm{l} 10 \mathrm{X}$ buffer, $0.4 \mu \mathrm{l} \mathrm{MgCl}$, 1.0ul dNTP, 0.25ul BSA, $0.2 \mu \mathrm{l}$ each of primers 2550 and 2718 (Fridolfsson and Ellegren, 1999), $1.0 \mu \mathrm{l}$ Taq polymerase, $3.75 \mu 1 \mathrm{H}_{2} \mathrm{O}$, and $2 \mu \mathrm{l}$ DNA in an Eppendorf thermocycler. Initial denaturing began at $94^{\circ} \mathrm{C}$ for $5 \mathrm{~min}$ followed by a touchdown sequence where the annealing temperature was lowered $1{ }^{\circ} \mathrm{C}$ per cycle from $94^{\circ}$ to $50^{\circ} \mathrm{C}$. A further 24 cycles were run with a denaturing temperature of $94^{\circ} \mathrm{C}$ for $30 \mathrm{~s}$, annealing temperature of $40^{\circ} \mathrm{C}$ for $30 \mathrm{~s}$ and extension of $72^{\circ} \mathrm{C}$ for $30 \mathrm{~s}$, followed by a final extension at $72^{\circ} \mathrm{C}$ for $2 \mathrm{~min}$ after the last cycle. PCR products were separated in a $3 \%$ agarose gel stained with ethidium bromide and run in $1 \mathrm{X}$ TBE buffer. Each gel was run with known male and female adult samples for comparison ( $N=273$ chicks).

\section{Statistical analyses}

All data have been deposited in the DataDryad data repository. We used R version 3.4 .3 (2017) to run all analyses, and statistical significance was claimed at $P<0.05$. During fieldwork we were generally blind to the experimental treatment, but not during statistical analysis. Sample sizes were determined by the number of breeding individuals in our study population that could be captured. To improve normality, all CORT values were $\log _{\mathrm{e}}$ transformed; all other metrics were untransformed. Raw means are reported \pm s.e. Sample sizes varied among analyses because we were not always able to collect all measurements from all individuals. We included 'year' as a factor only in analyses of maternal CORTinc, because during the nesting phase (CORTnest) we measured CORT in one year only (2016). To avoid possible carry-over effects of experimental treatment, females re-captured during the second year of the study were included for their first year of capture only. 
We constructed our statistical models including only main effects that were of likely biological importance and/or a priori interest; as such, not all twoway interactions were included. We report outputs from global statistical models. Because we had explicit hypotheses, and because none of our response variables was correlated, we did not to use a post-hoc correction for the number of tests performed (Perneger, 1998; Streiner, 2015).

\section{Morphological and hormonal measures of adult females}

We ran preliminary tests to determine whether females that had been assigned to CORT or Sham treatment groups differed in pre-implant body mass (measured at time of implant; females in the Control group were not captured prior to incubation and thus there was no pre-implant mass measurement). To test for possible differences in body size among treatments, we compared a female's wing length (measured pre-laying in the CORT and Sham treatments, and during early incubation in the Control females). Finally, we tested for differences in clutch initiation date in Julian days among treatments. Separate linear models (LM) were run with female pre-laying mass, wing length, and clutch initiation date as the response variable, and treatment (CORT, Sham, Control), site (Nature Area, Sewage Lagoon), year $(2015,2016)$, and age (SY, ASY) as the predictors. We did not include any interactions terms as they were not of a priori interest.

To test whether implanted females differed in their probability of recapture depending on treatment or year, we ran a generalized linear model (GLM) with binomial errors, with recapture status (recaptured/nonrecaptured) as the dependent variable, and treatment and year as the fixed effects. To test whether the total number of individuals that retained their implants and subsequently laid eggs differed between the CORT and Sham maternal treatment groups, we used a chi-square test (because Control females were only captured post-egg laying, they were not included in this analysis).

\section{Maternal baseline CORT during incubation and nestling stages}

To test whether treatment affected maternal CORT levels within each breeding stage (incubation and nestling), we used LM with either CORTinc or CORTnest as the response variable and maternal treatment, age, site, sample time (time from initial contact with bird to end of blood sample), and clutch initiation date (in Julian days) as fixed effects. We had no a priori predictions regarding interactions, so none was included in the models.

We analyzed CORTinc and CORTnest separately because CORTnest was only measured in 2016. Baseline CORTinc measurements $(N=59)$ had one suspected outlier $(121.22 \mathrm{ng} / \mathrm{ml})$ removed prior to analysis. This value was $>3$ standard deviations from the mean; considerably higher than the 0.5 to $14 \mathrm{ng} / \mathrm{ml}$ range reported previously (Franceschini et al., 2008; Ouyang et al., 2011a,b; Patterson et al., 2011; Hogle and Burness, 2014; Madliger et al., 2015). Preliminary analyses were run with and without this outlier, and although no difference was found in the pattern of significance of parameters, we chose to exclude it.

\section{Measures of female reproductive investment}

As indices of maternal investment during incubation we used clutch mass (summed mass of individual eggs at laying), and during the nestling phase we used maternal nest box visitation rate and nestling growth rate. To test whether a female's clutch mass correlated with her CORT levels, we used a LM with clutch mass as the response variable and CORTinc, maternal treatment, age, site, and year as main effects. To explore investment during the nestling stage, we used a LM with the number of nest box visits per chick per hour (by the female) as the response variable and CORTnest, treatment, maternal age, site, and male nest box visits per chick per hour as fixed effects. Finally, we calculated nestling growth rate per day during the linear growth phase (Burness et al., 2001) as the difference in individual mass between days 3 and 7 post-hatch, divided by 4 days. We used a linear mixed model (LMM, lmer in R package lme4) with individual chick mass gain per day as the response variable, and nest ID as a random effect. Fixed effects were CORTnest, maternal treatment, maternal age, site, nestling sex. To evaluate the possibility that maternal CORT may be linked with sex-specific investment in offspring (e.g. Love et al., 2005), we included an interaction between nestling sex and CORTnest.

\section{Measures of female reproductive success}

To test for a relationship between CORTinc and indices of reproductive success, we used a generalized linear mixed model (GLMM; glmer in R package lme4) with binomial errors, with either hatching or fledging success as the response variable ( 0 or 1 for each chick) and CORTinc, maternal treatment, age, site, and year as fixed effects, and nest ID as a random effect. To explore the relationship between CORTnest and post-hatching reproductive success, we examined individual nestling mass at day 14 posthatch and fledging success as indices of reproductive success. To test whether nestling mass differed with maternal CORT or treatment, we used a LMM with nestling mass at day 14 as the response variable and CORTnest, maternal treatment, maternal age, and site as fixed effects (year was not included because CORTnest was measured in 2016 only), and Nest ID as a random effect. Finally, to test whether fledging success differed with maternal CORT or treatment, fledging success ( 0 or 1 for each chick) was used as the response variable in a GLMM with binomial errors with maternal treatment, maternal age, site, and CORTnest as fixed effects, and Nest ID as a random effect. No interaction terms were included in these analyses

\section{Measures of female survival}

We estimated female survival by using the return rates of adult females to the study sites the following spring and comparing this with CORTinc or CORTnest during the previous year in separate models. Return rate (either 0 or 1) was the response variable in a GLM, with CORTinc (or CORTnest), treatment, year, age, site, and number of nestlings fledged as main effects. In analyses of CORTnest, 'year' was not included in the model because CORTnest was only measured in a single year (2016).

\section{Acknowledgements}

We thank Noah Ben-Ezra, Chantelle Penney and Aleesa Manax for their many hours of help in the field. Erica Nol, Joe Nocera, Jeff Bowman and an anonymous referee for providing numerous suggestions for improving the clarity of an earlier draft of the manuscript.

\section{Competing interests}

The authors declare no competing or financial interests.

\section{Author contributions}

Conceptualization: D.F., G.B.; Methodology: D.F., E.H.C., S.C., G.B.; Validation: D.F., E.H.C., S.C.; Formal analysis: D.F., R.R.M., G.B.; Investigation: D.F., E.H.C. Resources: G.B.; Data curation: D.F., R.R.M., G.B.; Writing - original draft: D.F.; Writing - review \& editing: D.F., R.R.M., E.H.C., G.B.; Visualization: D.F., R.R.M.; Supervision: G.B.; Project administration: G.B.; Funding acquisition: G.B.

\section{Funding}

Funding was provided by the Natural Sciences and Engineering Research Council of Canada (NSERC), the Canadian Foundation for Innovation and the Ontario Innovation Trust

\section{Data availability}

Data have been archived at the Dryad Digital Repository (https://doi.org/10.5061/ dryad.bcc2fqz8c).

\section{Supplementary information}

Supplementary information available online at

https://bio.biologists.org/lookup/doi/10.1242/bio.045898.supplemental

\section{References}

Angelier, F., Clement-chastel, C., Gabrielsen, G. and Chastel, O. (2007) Corticosterone and time-activity budget: an experiment with black-legged kittiwakes. Horm. Behav. 52, 482-491. doi:10.1016/j.yhbeh.2007.07.003

Astheimer, L. B., Buttemer, W. A. and Wingfield, J. C. (2000). Corticosterone treatment has no effect on reproductive hormones or aggressive behavior in freeliving male tree sparrows, Spizella arborea. Horm. Behav. 37, 31-39. doi:10.1006/ hbeh.1999.1555

Bentz, A. B., Navara, K. J. and Siefferman, L. (2013). Phenotypic plasticity in response to breeding density in tree swallows: An adaptive maternal effect? Horm. Behav. 64, 729-736. doi:10.1016/j.yhbeh.2013.08.009

Bleu, J., Gamelon, M. and Sæther, B. (2016). Reproductive costs in terrestrial male vertebrates: insights from bird studies. Proc. R. Soc. B 283, 1-9. doi:10.1098/rspb. 2015.2600 
Bonier, F. and Cox, R. M. (2020). Do hormone manipulations reduce fitness? A meta-analytic test of the Optimal Endocrine Phenotype Hypothesis. Mol. Cell. Endocrinol. 500, 110640. doi:10.1016/j.mce.2019.110640

Bonier, F., Martin, P. R., Moore, I. T. and Wingfield, J. C. (2009a). Do baseline glucocorticoids predict fitness? Trends Ecol. Evol. 24, 634-642. doi:10.1016/j. tree.2009.04.013

Bonier, F., Moore, I. T., Martin, P. R. and Robertson, R. J. (2009b). The relationship between fitness and baseline glucocorticoids in a passerine bird. Gen. Comp. Endocrinol. 163, 208-213. doi:10.1016/j.ygcen.2008.12.013

Bonier, F., Moore, I. T. and Robertson, R. J. (2011). The stress of parenthood? Increased glucocorticoids in birds with experimentally enlarged broods. Biol. Lett 7, 944-946. doi:10.1098/rsbl.2011.0391

Bortolotti, G. R., Marchant, T. A., Blas, J. and German, T. (2008). Corticosterone in feathers is a long-term, integrated measure of avian stress physiology. Funct Ecol. 22, 494-500. doi:10.1111/j.1365-2435.2008.01387.x

Bowers, E. K., Bowden, R. M., Thompson, C. F. and Sakaluk, S. K. (2016). Elevated corticosterone during egg production elicits increased maternal investment and promotes nestling growth in a wild songbird. Horm. Behav. 83 6-13. doi:10.1016/j.yhbeh.2016.05.010

Brown, C. R., Brown, M. B., Raouf, S. A., Smith, L. C. and Wingfield, J. C. (2005) Effects of endogenous steroid hormone levels on annual survival in cliff swallows. Ecology 86, 1034-1046. doi:10.1890/04-0740

Burness, G. P., Ydenberg, R. C. and Hochachka, P. W. (2001). Physiological and biochemical correlates of brood size and energy expenditure in tree swallows. J. Exp. Biol. 1501, 1491-1501.

Breuner, C. W. and Burk, S. A. (2019). Using the van Noordwijk and de Jong resource framework to evaluate glucocorticoid-fitness hypotheses. Integr. Comp. Biol. 59, 243-250. doi:10.1093/icb/icz088

Burtka, J. L., Lovern, M. B. and Grindstaff, J. L. (2016). Baseline hormone levels are linked to reproductive success but not parental care behaviors. Gen. Comp. Endocrinol. 229, 92-99. doi:10.1016/j.ygcen.2016.03.010

Chastel, O., Lacroix, A., Weimerskirch, H. and Gabrielssen, G. W. (2005) Modulation of prolactin but not corticosterone responses to stress in relation to parental effort in a long-lived bird. Horm. Behav. 47, 459-466. doi:10.1016/j. yhbeh.2004.10.009

Clark, R. G., Winkler, D. W., Dawson, R. D., Shutler, D., Hussell, D. J. T., Lombardo, M. P., Thorpe, P. A., Dunn, P. O. and Whittingham, L. A. (2018). Geographic variation and environmental correlates of apparent survival rates in adult tree swallows Tachycineta bicolor. J. Avian Biol. 49, 1-13. doi:10.1111/jav. 01659

Clinchy, M., Zanette, L., Charlier, T. D., Newman, A. E. M. and Schmidt, K. L. (2011). Multiple measures elucidate glucocorticoid responses to environmental variation in predation threat. Oecologia 166, 607-614. doi:10.1007/s00442-0111915-2

Criscuolo, F., Chastel, O., Bertile, F., Gabrielsen, G. W., Le Maho, Y. and Raclot, T. (2005). Corticosterone alone does not trigger a short term behavioural shift in incubating female common eiders Somateria mollissima, but does modify long term reproductive success. J. Avian Biol. 4, 306-312. doi:10.1111/j.0908-8857. 2005.03371.x

Crossin, G. T., Love, O. P., Cooke, S. J. and Williams, T. D. (2016). Glucocorticoid manipulations in free-living animals: considerations of dose delivery, life-history context and reproductive state. Funct. Ecol. 30, 116-125. doi:10.1111/1365-2435. 12482

Crossin, G. T., Phillips, R. A., Lattin, C. R., Romero, L. M. and Williams, T. D. (2013). Corticosterone mediated costs of reproduction link current to future breeding. Gen. Comp. Endocrinol. 193, 112-120. doi:10.1016/j.ygcen.2013. 07.011

Crossin, G. T., Trathan, P. N., Phillips, R. A., Gorman, K. B., Dawson, A., Sakamoto, K. Q. and Williams, T. D. (2012). Corticosterone predicts foraging behavior and parental care in macaroni penguins. Am. Nat. 180, E31-E41. doi:10. 1086/666001

Dantzer, B., Fletcher, Q. E., Boonstra, R. and Sheriff, M. J. (2014). Measures of physiological stress: a transparent or opaque window into the status, management and conservation of species? Conserv. Physiol. 2, 1-18. doi:10.1093/conphys/ cou023

Davis, J. E. and Guinan, J. A. (2014). Parental behavior correlates to baseline corticosterone of mates and offspring in nesting eastern bluebirds (Sialia sialis) Gen. Comp. Endocrinol. 201, 1-7. doi:10.1016/j.ygcen.2014.03.020

Franceschini, M. D., Custer, C. M., Custer, T. W., Reed, J. M. and Romero, L. M. (2008). Corticosterone stress response in tree swallows nesting near polychlorinated biphenyl- and dioxin-contaminated rivers. Environ. Toxicol. Chem. 27, 2326-2331. doi:10.1897/07-602.1

Fridolfsson, A. K. and Ellegren, H. (1999). A simple and universal method for molecular sexing of non-ratite birds. J. Avian Biol. 30, 116-121. doi:10.2307/ 3677252

Hansen, W. K., Bate, L. J., Landry, D. W., Chastel, O., Parenteau, C. and Breuner, C. W. (2016). Feather and faecal corticosterone concentrations predic future reproductive decisions in harlequin ducks (Histrionicus histrionicus). Conserv. Physiol. 4, 1-10. doi:10.1093/conphys/cow015
Harms, N. J., Legagneux, P., Gilchrist, H. G., Joël, B., Love, O. P., Forbes, M. R., Bortolotti, G. R. and Soos, C. (2014). Feather corticosterone reveals effect of moulting conditions in the autumn on subsequent reproductive output and survival in an Arctic migratory bird. Proc. R. Soc. B 282, 20142085. doi:10.1098/rspb. 2014.2085

Hau, M. and Goymann, W. (2015). Endocrine mechanisms, behavioral phenotypes and plasticity: known relationships and open questions. Front. Zool. 12, S7. doi:10.1186/1742-9994-12-S1-S7

Hayward, L. S. and Wingfield, J. C. (2004). Maternal corticosterone is transferred to avian yolk and may alter offspring growth and adult phenotype. Gen. Comp. Endocrinol. 135, 365-371. doi:10.1016/j.ygcen.2003.11.002

Henderson, L. J., Evans, N. P., Heidinger, B. J., Herborn, K. A. and Arnold, K. E. (2017). Do glucocorticoids predict fitness? Linking environmental conditions, corticosterone and reproductive success in the blue tit, Cyanistes caeruleus. R. Soc. Open Sci. 4, 170875. doi:10.1098/rsos.170875

Henriksen, R., Groothuis, T. G. G. and Rettenbacher, S. (2011). Elevated plasma corticosterone decreases yolk testosterone and progesterone in chickens: linking maternal stress and hormone-mediated maternal effects. PLOS ONE 6, 2-9. doi:10.1371/journal.pone.0023824

Hogle, N. C. and Burness, G. (2014). Sex-specific environmental sensitivity is transient in nestling Tree Swallows (Tachycineta bicolor). J. Ornithol. 155, 91-100. doi:10.1007/s10336-013-0991-y

Humphreys, E. M., Wanless, S. and Bryant, D. M. (2006). Stage-dependent foraging in breeding black-legged kittiwakes Rissa tridactyla: distinguishing behavioural responses to intrinsic and extrinsic factors. J. Avian Biol. 37, 436-446. doi:10.1111/j.2006.0908-8857.03594.x

Khan, N., Peters, R. A. and Robert, K. (2016). Compensating for a stressful start: maternal corticosterone, offspring survival, and size at fledging in the Zebra Finch, Taeniopygia guttata. Emu 116, 262-272. doi:10.1071/MU15095

Kleist, N. J., Guralnick, R. P., Cruz, A., Lowry, C. A. and Francis, C. D. (2018). Chronic anthropogenic noise disrupts glucocorticoid signaling and has multiple effects on fitness in an avian community. Proc. Natl. Acad. Sci USA 115 E648-E657. doi:10.1073/pnas.1709200115

Landys, M. M., Ramenofsky, M. and Wingfield, J. C. (2006). Actions of glucocorticoids at a seasonal baseline as compared to stress-related levels in the regulation of periodic life processes. Gen. Comp. Endocrinol. 148, 132-149. doi:10.1016/j.ygcen.2006.02.013

Lattin, C. R., Breuner, C. W. and Romero, L. M. (2016). Does corticosterone regulate the onset of breeding in free-living birds?: the CORT-Flexibility Hypothesis and six potential mechanisms for priming corticosteroid function. Horm. Behav. 78, 107-120. doi:10.1016/j.yhbeh.2015.10.020

Lendvai, ÁZ and Chastel, O. (2010). Natural variation in stress response is related to post-stress parental effort in male house sparrows. Horm. Behav. 58, 936-942. doi:10.1016/j.yhbeh.2010.09.004

Lendvai, ÁZ, Akçay, Ç, Ouyang, J. Q., Dakin, R., Domalik, A. D., St. John, P. S., Stanback, M., Moore, I. T. and Bonier, F. (2015). Analysis of the optimal duration of behavioral observations based on an automated continuous monitoring system in tree swallows (Tachycineta bicolor): Is one hour good enough? PLoS ONE 10 1-11. doi:10.1371/journal.pone.0141194

Love, O. P., Chin, E. H., Wynne-Edwards, K. E. and Williams, T. D. (2005). Stress hormones: a link between maternal condition and sex-biased reproductive investment. Am. Nat. 166, 751-766. doi:10.1086/497440

Love, O. P. and Williams, T. D. (2008). The adaptive value of stress-induced phenotypes: effects of maternally derived corticosterone on sex-biased investment, cost of reproduction, and maternal fitness. Am. Nat. 172 E135-E149. doi:10.1086/590959

Lucas, J. R., Freeberg, T. M., Egbert, J. and Schwabl, H. (2006). Fecal corticosterone, body mass, and caching rates of Carolina chickadees (Poecile carolinensis) from disturbed and undisturbed sites. Horm. Behav. 49, 634-643. doi:10.1016/j.yhbeh.2005.12.012

Madliger, C. L. and Love, O. P. (2016a). Conservation implications of a lack of relationship between baseline glucocorticoids and fitness in a wild passerine. Ecol. Appl. 26, 2730-2743. doi:10.1002/eap.1401

Madliger, C. L. and Love, O. P. (2016b). Do baseline glucocorticoids simultaneously represent fitness and environmental quality in a declining aeria insectivore? Oikos 125, 1824-1837. doi:10.1111/oik.03354

Madliger, C. L., Semeniuk, C. A. D., Harris, C. M. and Love, O. P. (2015) Assessing baseline stress physiology as an integrator of environmental quality in a wild avian population: Implications for use as a conservation biomarker. Biol. Conserv. 192, 409-417. doi:10.1016/j.biocon.2015.10.021

Martin, L. B., Gilliam, J., Han, P., Lee, K. and Wikelski, M. (2005). Corticosterone suppresses cutaneous immune function in temperate but not tropical house sparrows, Passer domesticus. Gen. Comp. Endocrinol. 140, 126-135. doi:10. 1016/j.ygcen.2004.10.010

Miller, D. A., Vleck, C. M. and Otis, D. L. (2009). Variation in baseline and stressinduced corticosterone and prolactin levels predicts parental effort by nesting mourning doves. Horm. Behav. 56, 457-464. doi:10.1016/j.yhbeh.2009.08.001 Nager, R. G. (2006). The challenges of making eggs. Ardea 94, 323-346. Newman, A. E. M., MacDougall-Shackleton, S. A., An, Y.-S., Kriengwatana, B. and Soma, K. K. (2010). Corticosterone and dehydroepiandrosterone have 
opposing effects on adult neuroplasticity in the avian song control system J. Comp. Neurol. 518, 3662-3678. doi:10.1002/cne.22395

Nilsson, J-Å and Råberg, L. (2001). The resting metabolic cost of egg laying and nestling feeding in great tits. Oecologia 128, 187-192. doi:10.1007/ s004420100653

Nomi, D. (2018). Male feeding contribution facilitates multiple brooding in a biparental songbird. Ibis 160, 293-300. doi:10.1111/ibi.12540

Ouyang, J. Q., Hau, M. and Bonier, F. (2011a). Within seasons and among years: when are corticosterone levels repeatable? Horm. Behav. 60, 559-564. doi:10. 1016/j.yhbeh.2011.08.004

Ouyang, J. Q., Sharp, P. J., Dawson, A., Quetting, M. and Hau, M. (2011b) Hormone levels predict individual differences in reproductive success in a passerine bird. Proc. R. Soc. B 278, 2537-2545. doi:10.1098/rspb.2010.2490

Ouyang, J. Q., Lendvai, AZ, Dakin, R., Domalik, A. D., Fasanello, V. J., Vassallo, B. G., Haussmann, M. F., Moore, I. T. and Bonier, F. (2015). Weathering the storm: parental effort and experimental manipulation of stress hormones predict brood survival. BMC Evol. Biol. 15, 1-8. doi:10.1186/s12862-015-0497-8

Ouyang, J. Q., Muturi, M., Quetting, M. and Hau, M. (2013). Small increases in corticosterone before the breeding season increase parental investment but not fitness in a wild passerine bird. Horm. Behav. 63, 776-781. doi:10.1016/j.yhbeh. 2013.03.002

Pakkala, J. J., Norris, D. R., Sedinger, J. S. and Newman, A. E. M. (2016) Experimental effects of early-life corticosterone on the hypothalamic-pituitaryadrenal axis and pre-migratory behaviour in a wild songbird. Funct. Ecol. 30 , 1149-1160. doi:10.1111/1365-2435.12603

Patterson, S. H., Hahn, T. P., Cornelius, J. M. and Breuner, C. W. (2014). Natura selection and glucocorticoid physiology. J. Evol. Biol. 27, 259-274. doi:10.1111/ jeb.12286

Patterson, S. H., Winkler, D. W. and Breuner, C. W. (2011). Glucocorticoids individual quality and reproductive investment in a passerine bird. Anim. Behav. 81, 1239-1247. doi:10.1016/j.anbehav.2011.03.012

Perneger, T. V. (1998). What's wrong with Bonferroni adjustments. Brit. Med. J. 316 1236-1238. doi:10.1136/bmj.316.7139.1236

Pitk, M., Tilgar, V., Kilgas, P. and Mänd, R. (2012). Acute stress affects the corticosterone level in bird eggs: a case study with great tits (Parus major). Horm Behav. 62, 475-479. doi:10.1016/j.yhbeh.2012.08.004

Pyle, P., Howell, S. N. G., Yuick, R. P. and DeSante, D. F. (1987). Identification Guide to North American Passerines. Bolinas, USA: Slate Creek Press.

Riechert, J., Becker, P. H. and Chastel, O. (2014). Predicting reproductive success from hormone concentrations in the common tern (Sterna hirundo) while considering food abundance. Oecologia 176, 715-727. doi:10.1007/s00442014-3040-5

Rivers, J. W., Newberry, G. N., Schwarz, C. J. and Ardia, D. R. (2017). Success despite the stress: violet-green swallows increase glucocorticoids and maintain reproductive output despite experimental increases in flight costs. Funct. Ecol. 31, 235-244. doi:10.1111/1365-2435.12719

Robertson, B. D., Newman, A. E. M. and MacDougall-Shackleton, S. A. (2015) Perils and pitfalls of manipulating glucocorticoids with silicone implants. Integr. Comp. Biol. 55, E154.

Romero, L. M. (2002). Seasonal changes in plasma glucocorticoid concentrations in free-living vertebrates. Gen. Comp. Endocrinol. 128, 1-24. doi:10.1016/S0016 6480(02)00064-3

Romero, L. M. (2004). Physiological stress in ecology: lessons from biomedical research. Trends Ecol. Evol. 19, 249-255. doi:10.1016/j.tree.2004.03.008

Romero, L. M. and Fairhurst, G. D. (2016). Measuring corticosterone in feathers: strengths, limitations, and suggestions for the future. Comp. Biochem. Physiol. A 202, 112-122. doi:10.1016/j.cbpa.2016.05.002

Saino, N., Romano, M., Ferrari, R. P., Martinelli, R. and Møller, A. P. (2005) Stressed mothers lay eggs with high corticosterone levels which produce lowquality offspring. J. Exp. Zool. A 303, 998-1006. doi:10.1002/jez.a.224

Sakaluk, S. K., Thompson, C. F. and Bowers, E. K. (2018). Experimental manipulation of incubation period reveals no apparent costs of incubation in house wrens. Anim. Behav. 137, 169-177. doi:10.1016/j.anbehav.2018.01.006

Sapolsky, R. M., Romero, L. M. and Munck, A. U. (2000). How do glucocorticoids influence stress responses? Integrating permissive, suppressive, stimulatory, and preparative actions. Endocr. Rev. 21, 55-89. doi:10.1210/er.21.1.55

Schoech, S. J., Bowman, R., Bridge, E. S. and Boughton, R. K. (2007). Baseline and acute levels of corticosterone in Florida scrub-jays (Aphelocoma coerulescens): effects of food supplementation, suburban habitat, and year. Gen. Comp. Endocrinol. 154, 150-160. doi:10.1016/j.ygcen.2007.05.027
Schoenle, L. A., Dudek, A. M., Moore, I. T. and Bonier, F. (2017). Red-winged blackbirds (Agelaius phoeniceus) with higher baseline glucocorticoids also invest less in incubation and clutch mass. Horm. Behav. 90,1-7. doi:10.1016/j.yhbeh. 2017.02.002

Schoenle, L. A., Zimmer, C., Miller, E. T. and Vitousek, M. N. (2021). Does variation in glucocorticoid regulation predict fitness? A phylogenetic metaanalysis. Gen. Comp. Endocrinol. 300, 113611. doi:10.1016/j.ygcen.2020. 113611

Shitikov, D. A., Vaytina, T. M., Makarova, T. V., Fedotova, S. E., Krasnykh, N. A. and Yurchenko, Y. A. (2017). Breeding success affects the apparent survival of grassland passerines. Biol. Bull 44, 1046-1055. doi:10.1134/ S1062359017090138

Sorenson, G. H., Dey, C. J., Madliger, C. L. and Love, O. P. (2017). Effectiveness of baseline corticosterone as a monitoring tool for fitness: a meta-analysis in seabirds. Oecologia 183, 353-365. doi:10.1007/s00442-016-3774-3

Streiner, D. L. (2015). Best (but oft-forgotten) practices: the multiple problems of multiplicity-whether and how to correct for many statistical tests. Amer. J. Clin Nutr. 102, 721-728. doi:10.3945/ajcn.115.113548

Thierry, A.-M., Ropert-Coudert, Y. and Raclot, T. (2013). Elevated corticosterone levels decrease reproductive output of chick-rearing Adélie penguins but do not affect chick mass at fledging. Conserv. Physiol. 1, 1-12. doi:10.1093/conphys/ cot007

Torres-Medina, F., Cabezas, S., Marchant, T. A., Wikelski, M., Romero, L. M. Hau, M., Carrete, M., Tella, J. L. and Blas, J. (2018). Corticosterone implants produce stress-hyporesponsive birds. J. Exp. Biol. 221, jeb173864. doi:10.1242/ jeb.173864

Tulp, I., Bruinzeel, L. W., Jukema, J. and Visser, G. H. (2009). Energetic demands during incubation and chick rearing in a uniparental and a biparental shorebird breeding in the high arctic. Auk 126, 155-164. doi:10.1525/auk.2009.07181

Vitousek, M. N., Jenkins, B. R. and Safran, R. J. (2014). Stress and success: individual differences in the glucocorticoid stress response predict behavior and reproductive success under high predation risk. Horm. Behav. 66, 812-819. doi:10.1016/j.yhbeh.2014.11.004

Vitousek, M. N., Taff, C. C., Hallinger, K. K. and Zimmer, C. (2018). Hormones and fitness: evidence for trade-offs in glucocorticoid regulation across contexts. Front. Ecol. Evol. 6, 1-14. doi:10.3389/fevo.2018.00042

Washburn, B. E., Morris, D. L., Millspaugh, J. J., Faaborg, J. and Schulz, J. H. (2002). Using a commercially available radioimmunoassay to quantify corticosterone in avian plasma. Condor 104, 558-563. doi:10.1093/condor/104. 3.558

Weegman, M. D., Arnold, T. W., Dawson, R. D., Winkler, D. W. and Clark, R. G. (2017). Integrated population models reveal local weather conditions are the key drivers of population dynamics in an aerial insectivore. Oecologia 185, 119-130. doi:10.1007/s00442-017-3890-8

Whittingham, L. A., Dunn, P. O. and Clotfelter, E. D. (2003). Parental allocation of food to nestling tree swallows: the influence of nestling behaviour, sex and paternity. Anim. Behav. 65, 1203-1210. doi:10.1006/anbe.2003.2178

Wilcoxen, T. E., Boughton, R. K., Bridge, E. S., Rensel, M. A. and Schoech, S. J. (2011). Age-related differences in baseline and stress-induced corticosterone in Florida scrub-jays. Gen. Comp. Endocrinol. 173, 461-466. doi:10.1016/j.ygcen. 2011.07.007

Williams, T. D. (2005). Mechanisms underlying the costs of egg production. Bioscience 55, 39-48. doi:10.1641/0006-3568(2005)055[0039:MUTCOE]2.0. $\mathrm{CO} ; 2$

Williams, T. D. (2018). Physiology, activity and costs of parental care in birds. J. Exp. Biol. 221, jeb169433. doi:10.1242/jeb.169433

Wingfield, J. C., Maney, D. L., Breuner, C. W., Jacobs, J. D., Lynn, S., Ramenofsky, M. and Richardson, R. D. (1998). Ecological bases of hormonebehavior interactions: the "emergency life history stage". Am. Zool. 206, 191-206. doi:10.1093/icb/38.1.191

Wingfield, J. C. and Sapolsky, R. M. (2003). Reproduction and resistance to stress: when and how. J. Neuroendocrinol. 15, 711-724. doi:10.1046/j.1365-2826.2003. 01033.x

Wingfield, J. C., Weimerskirch, H. and Chastel, O. (2010). Hormonal correlates of individual quality in a long-lived bird: a test of the 'corticosterone-fitness hypothesis'. Biol. Lett. 6, 846-849. doi:10.1098/rsbl.2010.0376

Winkler, D. W., Hallinger, K. K., Ardia, D. R., Robertson, R. J., Stutchbury, B. J. and Cohen, R. R. (2020). Tree Swallow (Tachycineta bicolor), version 1.0. In Birds of the World (ed. A. F. Poole). New York: Cornell Lab of Ornithology. doi:10. 2173/bow.treswa.01 